\title{
Seleção de refratários para fornos de cozimento de anodo
}

\section{(Refractories selection for anode baking furnace)}

\author{
P.R.T.Tiba ${ }^{1}$, B. H. Teider ${ }^{2}$, F. Figueiredo ${ }^{3}$, J. B. Gallo', V. C. Pandolfelli ${ }^{1}$ \\ ${ }^{I}$ Grupo de Engenharia de Microestrutura de Materiais - GEMM, Departamento de Engenharia de Materiais, \\ Universidade Federal de S. Carlos, Rod. Washington Luiz, km 235, C.P. 676, S. Carlos, SP 13565-905 \\ ${ }^{2}$ Alcoa Alumínio S.A., Departamento de Aplicações, Desenvolvimentos \& VPE, Rod. Poços-Andradas, km 10, \\ Poços de Caldas, $M G$ \\ ${ }^{3}$ Consórcio de Alumínio do Maranhão, Aluma, Departamento de Carbono e Tecnologia, BR 135, km 18, S. Luis, MA \\ tiba_em03@yahoo.com.brouvicpando@power.ufscar.br
}

\begin{abstract}
Resumo
Nos últimos anos a produção mundial de alumínio tem aumentado e para as empresas continuarem competitivas torna-se necessário que a média do custo de produção do metal seja reduzida. Uma das alternativas é aumentar a vida útil dos refratários usados em fornos de cozimento de anodo, bem como a sua capacidade de produção. Ambas estratégias podem resultar em maior qualidade do anodo e redução no custo de manutenção do forno. O presente trabalho tem por objetivo apresentar a caracterização termo-mecânica dos tijolos refratários utilizados em fornos de cozimento de anodo e a resistência destes materiais ao ataque químico. Os resultados indicam que a escolha da composição mais adequada depende de uma análise sistêmica das propriedades a alta temperatura, da resistência química e das práticas operacionais do forno.
\end{abstract}

Palavras-chave: alumínio, refratário, anodo.

\begin{abstract}
In the latest years the worldwide production of aluminum is increasing and for the companies to keep their competitiveness it is necessary to reduce the average cost of the metal production. One of the alternatives is to increase the refractories working life used in anode baking furnaces and their production capacity. Both strategies may result in a higher anode quality and reduction of the furnace maintenance costs. This paper aims to present the thermo-mechanical characterization of the refractory bricks used in anode baking furnaces and their resistance to chemical attack. The results indicated that the selection of the most suitable composition depends on a systemic analysis involving the high temperature properties, chemical resistance and the operational practices of the furnace.
\end{abstract}

Keywords: aluminum, refractory, anode.

\section{INTRODUÇÃO}

Com a crescente expansão do consumo e produção de alumínio no mundo, algumas empresas, para continuarem competitivas, optam por reduzir o custo médio de produção do metal primário. Uma alternativa interessante para se alcançar este objetivo é a adequada seleção dos materiais refratários que compõem os fornos de cozimentos de anodo em plantas com a tecnologia pre-baked para cubas eletrolíticas.

Atualmente, o cozimento do anodo é uma das etapas mais caras da produção de alumínio [1] e um pequeno aumento na qualidade dos tijolos refratários resulta em consideráveis economias, além de facilitar as práticas operacionais do forno [2]. Visando aprimorar a qualidade e a produtividade dos anodos cozidos, desenvolvimentos tecnológicos nos fornos vêm sendo constantemente efetuados. Recentemente, avanços no controle de processo e de queima, permitiram que as empresas optassem por fornos de tipo aberto em detrimento aos fechados, devido aos ganhos em produtividade e redução do consumo de combustível [3].

A operação de cozimento dos anodos é definida em 5 etapas principais: enfornamento dos anodos, préaquecimento, queima, resfriamento e desenfornamento dos blocos anódicos. A Alumar, um dos maiores produtores de alumínio da América Latina, possui 3 fornos do tipo aberto que produzem 680 anodos por dia [4]. A etapa de queima é realizada em temperaturas de $1230-1250{ }^{\circ} \mathrm{C}$, porém, os refratários podem estar sujeitos a temperaturas da ordem de $1400-1500{ }^{\circ} \mathrm{C}$, nas proximidades do queimadores [2]. No entanto, a queima não é o único fator a influenciar a vida útil dos tijolos. O projeto do forno, a operação e o ataque químico, também são responsáveis pelo desempenho dos refratários utilizados [5].

\section{Projeto do forno}

Atualmente, o projeto do forno da Alumar consiste 
basicamente de tijolos denominados "Flue Wall Brick" que compõem as paredes do forno de $5 \mathrm{~m}$ de altura, aproximadamente. As junções estruturais entre estas paredes são realizadas por tijolos do tipo "Tie Brick", permitindo uma maior estabilidade dimensional, conforme a Fig. 1.

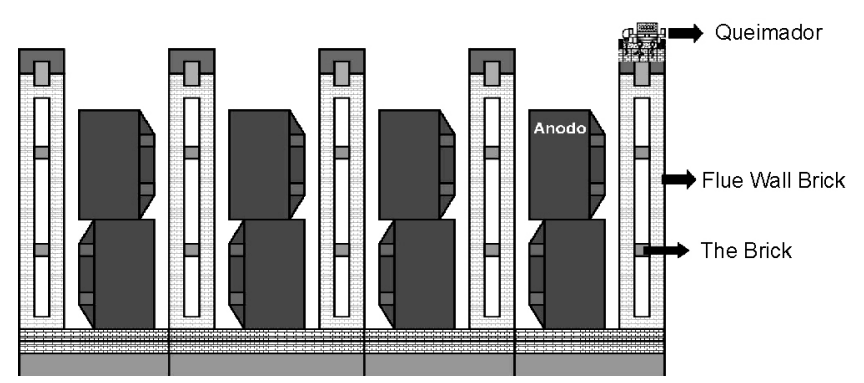

Figura 1: Esquema do forno de anodo.

[Figure 1: Anode furnace section.]

A tecnologia de posicionamento dos refratários influencia indiretamente na qualidade do anodo, pois é possível otimizar a distribuição do calor, apenas alterando a posição dos "Tie Brick", que atuam como defletores de calor [6]. Adicionalmente, estes materiais devem possuir uma elevada resistência mecânica e resistir a deformação, ambas a alta temperatura, devido a massa específica da estrutura (tijolos refratários e anodos).

\section{Operação do forno}

As práticas operacionais do forno são determinantes na vida útil dos materiais utilizados. Durante o carregamento e descarregamento dos anodos, tensões mecânicas geram trincas nas paredes, resultando em substituições dos tijolos. Além disso, a operação de limpeza do coque impregnado nas paredes danifica os refratários, aumentando o custo de manutenção. De acordo com Hurlen et al, a estimativa do custo de manutenção pode ser calculada por meio da razão entre a quantidade de refratário substituída pela tonelada de anodo cozido produzido [7]. Alguns desenvolvimentos recentes em fornos de anodo minimizam os danos nos refratários pela implementação de controles estatísticos de processo (SPC), conversão para defletores triplos nas paredes, injeção de combustível pontual, entre outros [8]. Adicionalmente, alguns modelos matemáticos podem ser adotados como importante ferramenta para o entendimento e controle de processo, bem como do projeto do forno [9]. Portanto, o processo de cozimento de anodo é diretamente interligado com a escolha do refratário.

\section{Condições de queima}

A primeira etapa da queima consiste no préaquecimento do anodo cujo objetivo principal é retirar gases voláteis presentes no piche. Esta região é controlada basicamente pelo calor liberado da queima do anodo, na zona de cozimento do forno, e da queima resultante dos gases voláteis [4]. A segunda etapa consiste do tratamento térmico do anodo, onde este adquire as propriedades desejadas para sua utilização: elevada densidade, baixa resistividade elétrica, elevada condutividade térmica, baixa reatividade ao ar e ao $\mathrm{CO}_{2}$, além de baixa permeabilidade ao ar e elevada resistência à flexão [10]. Após o cozimento, o anodo é resfriado e transportado à Sala de Cubas, onde fará parte da reação de oxi-redução da alumina em alumínio. Portanto, este ciclo de queima gera choque térmico nos refratários dos fornos, resultando em trincas que deterioram as propriedades termomecânicas dos materiais.

Modelos computacionais, como o "Computacional Fluid Dynamics - CFD”, podem melhorar a distribuição de calor nos fornos. O CFD também pode ser usado como ferramenta de controle, pois, possibilita novas visualizações do processo de queima [11]. Adicionalmente, verificou-se que o consumo de combustível pode ser influenciado tanto pelos programas computacionais quanto pelo refratário, pois cerca de $28 \%$ da energia térmica do forno é armazenada nos tijolos refratários [12].

\section{Ataque químico}

A corrosão química é um fenômeno típico em fornos de cozimento do tipo aberto, onde há deposição de coque de recobrimento do anodo nos poros dos refratários e em juntas de expansão, além do ataque químico de outros elementos presentes nos fornos. O comportamento de corrosão é determinado por fatores como migração de gases e líquidos, redução dos componentes óxidos dos tijolos e processos de recristalização [13].

Há basicamente quatro elementos nos fornos de anodo que podem ser deletérios aos refratários: álcalis (presentes no coque, combustíveis e nos próprios tijolos), pentóxidos de vanádio (oriundo do combustível), fluoretos (presente na composição do anodo verde) e monóxido e dióxido de carbono (relacionados à atmosfera redutora do forno) [5]. A combinação do vanádio, oriundo do combustível, com o sódio, presente no coque reciclado, resulta em fases de baixo ponto de fusão [14]. Visando elevar a resistência ao ataque químico destes refratários, alguns desenvolvimentos foram efetuados. O uso de andalusita em substituição às argilas, resulta em tijolos de alta resistência ao ataque por álcalis e vanádio, elevado desempenho termo-mecânico e elevada condutividade térmica [5]. Foi também sugerida a utilização de andalusita na matriz devido à redução de fase liquida durante a corrosão por sódio gasoso [16]. Portanto, pela literatura, recomenda-se o uso de matérias primas com alto teor de alumina e baixo teor de óxido de ferro, além de mulita, coríndon e cristobalita como fases principais constituintes dos refratários de alto desempenho [5, 1618]. Embora avanços tenham sido obtidos com relação ao projeto do forno, condições de queima, ataque químico e desenvolvimento de materiais, a literatura pouco destaca 
o processo de seleção dos refratários, elemento vital na otimização de todos estes parâmetros. Desta forma, o presente trabalho tem por objetivo otimizar o processo de seleção dos refratários utilizados em fornos de cozimento de anodo, por meio da caracterização termo-mecânica e da resistência ao ataque químico destes materiais.

\section{MATERIAIS E MÉTODOS}

Para a seleção de refratários para fornos de cozimento de anodo, foram escolhidos sete composições de cinco fornecedores distintos de refratários. As amostras foram confeccionadas em laboratório a partir de tijolos fornecidos pelos próprios fabricantes.

A análise química dos materiais foi realizada de acordo com a norma ASTM C-573. Para cada composição, 200 $\mathrm{g}$ de material foram preparados por meio da moagem em moinho de carbeto de tungstênio e as análises foram realizadas em um equipamento de florescência por raios Phillips PW1440.

O módulo de ruptura a alta temperatura foi medido conforme a norma ASTM C583. Cinco amostras $\left(150 \times 25 \times 25 \mathrm{~mm}^{3}\right)$ de cada composição foram testadas a $1371{ }^{\circ} \mathrm{C}$ com taxa de carregamento de $12,5 \mathrm{~N} / \mathrm{s}$ em equipamento Netzsch HBST 422.

Para o teste de fluência, a taxa de aquecimento foi de $5{ }^{\circ} \mathrm{C} / \mathrm{min}$, sob 0,20 MPa de tensão de compressão, com patamar de $100 \mathrm{~h}$ à $1427^{\circ} \mathrm{C}$. Tijolos com $50 \%$ de alumina também foram testados à $1227^{\circ} \mathrm{C}$, que é uma condição mais realista das operações do forno.

As propriedades analisadas bem como as normas utilizadas são apresentadas na Tabela I.

Tabela I - Testes e normas para caracterização dos refratários para fornos de anodo.

[Table I - Tests and standards for anode furnace refractory characterization.]

\begin{tabular}{|c|c|c|}
\hline Propriedade & Unidade & Norma \\
\hline Análise Química & $\%$ peso & ASTM C-573 \\
\hline $\begin{array}{c}\text { Resistência Mecânica a } \\
\text { Alta Temperatura } \\
\left(1371^{\circ} \mathrm{C}\right)\end{array}$ & $\mathrm{MPa}$ & ASTM C-583 \\
\hline $\begin{array}{c}\text { Fluência } \\
\left(100 \text { h a } 1427^{\circ} \mathrm{C} \text { sob } 0,2\right. \\
\left.\mathrm{N} / \mathrm{mm}^{2} \text { compressão }\right)\end{array}$ & $\%$ & DIN 51053 \\
\hline $\begin{array}{c}\text { Refratariedade sob Carga } \\
\left(5^{\circ} \mathrm{C} / \mathrm{min} \text { até } 1427^{\circ} \mathrm{C} \text { sob }\right. \\
\left.0,2 \mathrm{~N} / \mathrm{mm}^{2} \text { compressão }\right)\end{array}$ & ${ }^{\circ} \mathrm{C}$ & DIN 51053 \\
\hline $\begin{array}{c}\text { Resistência ao } \\
\text { Choque Térmico } \\
\left(6 \text { ciclos }-\Delta \mathrm{T}=1000{ }^{\circ} \mathrm{C}\right)\end{array}$ & $\begin{array}{l}\% \text { ou } \\
\mathrm{MPa}\end{array}$ & ASTM C1171 \\
\hline Ataque Químico & $\mathrm{mm}^{2}$ & Norma Interna \\
\hline
\end{tabular}

A refratariedade $\left(\mathrm{T}_{0,5 \%}\right)$ dos materiais pode ser considerada como a temperatura na qual as amostras deformam $0,5 \%$ após a temperatura de início de amolecimento sob compressão. Os testes foram realizados a uma taxa de aquecimento de $5{ }^{\circ} \mathrm{C} /$ min até $1427^{\circ} \mathrm{C}$, sob uma tensão de compressão de $0,20 \mathrm{MPa}$. Tanto o teste de fluência quanto o de refratariedade sob carga foram realizados em equipamento Netzsch RUL 421E.

A avaliação da resistência dos materiais ao choque térmico foi baseada na norma ASTM C1171 que consiste em 6 ciclos térmicos com 15 min a $1000^{\circ} \mathrm{C}$ seguido de 15 min à temperatura ambiente. A queda porcentual do modulo elástico e o módulo residual da resistência mecânica após a ciclagem térmica são os parâmetros usados na avaliação dos materiais. O modulo elástico após 3 e 6 ciclos foram estimados no equipamento Scanelastic, desenvolvido pela ATCP do Brasil em parceria com o GEMM, e o módulo de ruptura após o choque térmico foi avaliado no equipamento MTS $810 \mathrm{com}$ Teststar II station em um ensaio de flexão por 3 pontos com distância entre os apoios de $125 \mathrm{~mm}$. A taxa de carregamento foi de 12,9 N/s conforme a norma ASTM C133.

O cup test ou ataque químico foi realizado de acordo com o procedimento utilizado por Carrol e Grobbelaar [5], no qual um tijolo com orifício de $50 \mathrm{~mm}$ de diâmetro x $50 \mathrm{~mm}$ de profundidade é preenchido com $15 \mathrm{~g}$ de criolita e coberto por $15 \mathrm{~g}$ de coque metalúrgico. A amostra é queimada a $1300{ }^{\circ} \mathrm{C}$ por $12 \mathrm{~h} \mathrm{e}$, após o tratamento térmico, os tijolos são cortados no sentido transversal e a área atacada é estimada pelo software "Image Analyzer". Para cada composição foram efetuados dois testes de corrosão.

\section{RESULTADOS E DISCUSSÃO}

\section{Análise química}

De acordo com a análise química dos materiais, duas classes de materiais foram observadas: uma com maior teor de alumina, aproximadamente, 60\%-peso (amostras A e F) e, a outra, com 50\%-p de alumina. Desta forma, verifica-se no mercado dois tipos de refratários para fornos de cozimento de anodo. Os tijolos de alta refratariedade que são geralmente usados como travamento das paredes dos condutos, ou seja, possuem função de ligação das paredes (Tie Bricks) e, materiais, de 50\%-p de alumina, que compõem as paredes refratárias que tem contato direto com o coque de recobrimento do anodo (Flue Wall Bricks). Geralmente, o comportamento dos materiais a alta temperatura é influenciado pelo teor de $\mathrm{Fe}_{2} \mathrm{O}_{3}$ e $\mathrm{TiO}_{2}$ que geram fases de baixo ponto de fusão. A literatura mostra que a redução do teor de álcalis do material otimiza as propriedades dos materiais, pois, estes quando combinados com vanádio comprometem a refratariedade do material [14].

\section{Resistência mecânica a alta temperatura}

Considerando o módulo de ruptura a alta temperatura (Fig. 2), observam-se dois grupos distintos de materiais. O 
Tabela II - Análise química das composições.

[Table II - Compositions chemical analysis.]

\begin{tabular}{cccccc}
\hline & $\mathrm{Al}_{2} \mathrm{O}_{3}(\%)$ & $\mathrm{SiO}_{2}(\%)$ & $\mathrm{Fe}_{2} \mathrm{O}_{3}(\%)$ & $\mathrm{Na}_{2} \mathrm{O}+\mathrm{K}_{2} \mathrm{O}(\%)$ & $\mathrm{CaO}+\mathrm{MgO}(\%)$ \\
\hline $\mathrm{A}$ & 60,84 & 36,70 & 0,99 & 0,45 & 0,31 \\
$\mathrm{~B}$ & 48,80 & 48,54 & 0,86 & 0,28 & 0,21 \\
$\mathrm{C}$ & 49,37 & 47,22 & 0,96 & 0,30 & 0,17 \\
$\mathrm{D}$ & 48,85 & 46,73 & 1,39 & 0,17 & 0,18 \\
$\mathrm{E}$ & 49,15 & 46,25 & 0,93 & 0,54 & 0,15 \\
$\mathrm{~F}$ & 63,25 & 34,75 & 0,87 & 0,23 & 0,13 \\
$\mathrm{G}$ & 50,47 & 43,84 & 1,64 & 0,11 & 0,08 \\
\hline
\end{tabular}

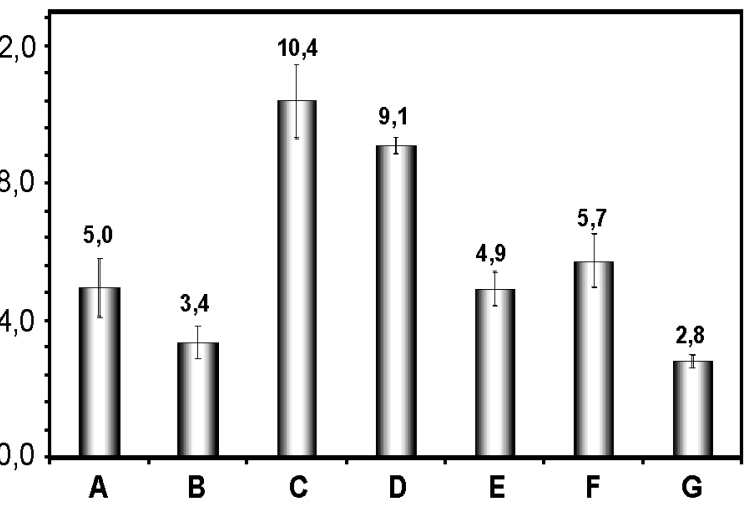

Figura 2: Módulo de ruptura a quente a $1371^{\circ} \mathrm{C}$. [Figure 2: Hot modulus of rupture at $1371^{\circ} \mathrm{C}$.]

primeiro, com elevada resistência mecânica, acima de 9,0 MPa e, o segundo, com resistência mecânica inferior a 6,0 $\mathrm{MPa}$. Um aspecto importante é que apenas os materiais importados $(\mathrm{C}$ e D) resultaram em alta resistência mecânica à elevada temperatura. Provavelmente, estes materiais possuem uma microestrutura diferenciada, com menor tamanho de grão e/ou matérias primas mais nobres.

Importante ressaltar que as composições com $60 \%$ de alumina, A e F, obtiveram valores intermediários de resistência mecânica a quente. Isto demonstra que não há uma correlação clara entre o teor de alumina ou mesmo o teor de álcalis e a resistência mecânica a alta temperatura. Adicionalmente, indica que fatores microestruturais determinam o desempenho dos materiais. Tais refratários são usualmente produzidos com matérias primas naturais calcinadas, o que dificulta muito uma clara correlação entre a propriedade e a composição, como ocorre para as sintéticas.

\section{Fluência}

De acordo com a Fig. 3 e a Tabela III, verifica-se uma discrepância na deformação dos materiais a $1427{ }^{\circ} \mathrm{C}$. As composições A e $\mathrm{F}$ resultaram valores de deformação menores que $1,0 \%$, indicando que a resistência a fluência pode estar correlacionada com seus altos teores de alumina. Como verificado, esta classe de materiais também possui elevado tamanho de grão, conferindo ao material uma alta resistência a fluência devido ao engastamento destas partículas sob compressão. No entanto, este maior tamanho de partícula também resulta em defeitos superiores, o que pode ser comprovado pela baixa resistência mecânica a alta temperatura destes materiais.

Considerando apenas os materiais com 50\% de alumina, as composições importadas, $\mathrm{C}$ e D, obtiveram os melhores desempenhos, mas, com valores de deformação bem acima das composições de alta refratariedade.

Para uma melhor condição de ensaio que efetivamente simule as práticas operacionais do forno, realizou-se o ensaio de fluência a $1227^{\circ} \mathrm{C}$ apenas para a classe de materiais com $50 \%$ de alumina, visto que, as composições de alta refratariedade já apresentaram baixa deformação à $1427^{\circ} \mathrm{C}$.

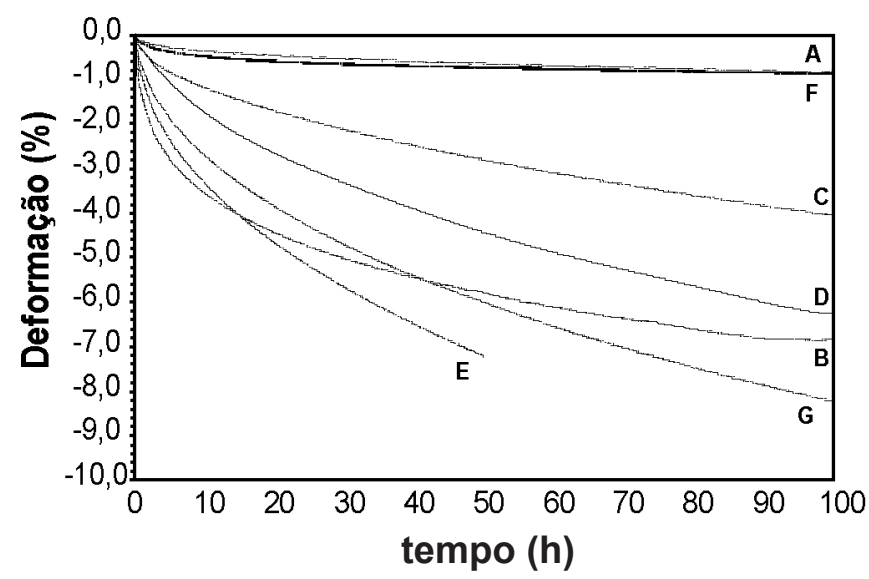

Figura 3: Fluência a $1427^{\circ} \mathrm{C}$ por $100 \mathrm{~h}$.

[Figure 3: Creep at $1427^{\circ} \mathrm{C}$ for $\left.100 \mathrm{~h}.\right]$

Tabela III - Deformação por fluência a $1427^{\circ} \mathrm{C}$ por $100 \mathrm{~h}$. [Table III - Creep deformation at $1427^{\circ} \mathrm{C}$ for $100 \mathrm{~h}$. ]

\begin{tabular}{cccccccc}
\hline & $\mathrm{A}$ & $\mathrm{B}$ & $\mathrm{C}$ & $\mathrm{D}$ & $\mathrm{E}$ & $\mathrm{F}$ & $\mathrm{G}$ \\
\hline $\begin{array}{c}\text { Deformação } \\
(\%)\end{array}$ & 0,84 & 6,85 & 4,04 & 6,31 & $7,20^{*}$ & 0,86 & 8,23 \\
\hline
\end{tabular}

* Após 50 h, o ensaio da amostra E foi interrompido devido a alta deformação apresentada. 
Pela Fig. 4 e Tabela IV observa-se que os materiais importados $(\mathrm{C}$ e $\mathrm{D})$ resultaram em elevada resistência à deformação, indicando que estas composições possuem uma microestrutura diferenciada. No entanto, para aplicações a $1227^{\circ} \mathrm{C}$, qualquer composição poderia ser utilizada devido aos valores de deformação por fluência serem inferiores a $1,0 \%$.

\section{Refratariedade sob carga}

Os materiais com $60 \%$ de alumina e a composição $\mathrm{C}$ apresentaram elevado desempenho, resultando em temperaturas de amolecimento superiores a $1250{ }^{\circ} \mathrm{C}$. As demais composições apresentaram temperaturas de amolecimento inferiores a $1200{ }^{\circ} \mathrm{C}$ e, tendo em vista que a queima ocorre entre $1230{ }^{\circ} \mathrm{C}$ e $1250{ }^{\circ} \mathrm{C}$, estes materiais não atendem as solicitações desejadas. Em relação à temperatura para deformação de $0,5 \%$, todas as composições tiveram resultados superiores a 1427 ${ }^{\circ} \mathrm{C}$, exceto as composições B e $\mathrm{G}$, com temperaturas próximas a $1400{ }^{\circ} \mathrm{C}$. Desta forma, conclui-se que estes dois materiais, se escolhidos, podem prejudicar as operações dos fornos.

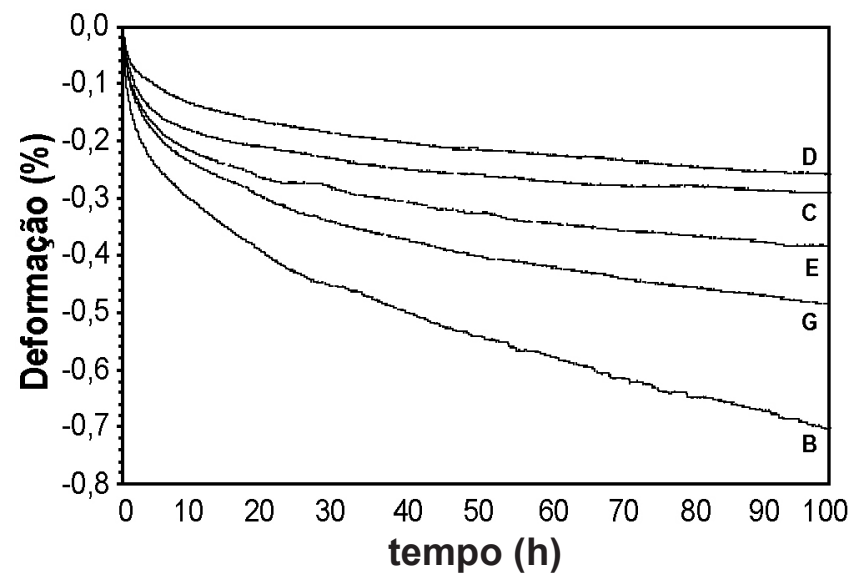

Figura 4: Fluência a $1227^{\circ} \mathrm{C}$ por $100 \mathrm{~h}$.

[Figure 4: Creep at $1227^{\circ} \mathrm{C}$ for $100 \mathrm{~h}$.]

Tabela IV - Deformação por fluência a $1227^{\circ} \mathrm{C}$ por $100 \mathrm{~h}$. [Table IV - Creep deformation at $1227^{\circ} \mathrm{C}$ for $100 \mathrm{~h}$.]

\begin{tabular}{cccccccc}
\hline & A & B & C & D & E & F & G \\
\hline $\begin{array}{c}\text { Deformação } \\
(\%)\end{array}$ & - & 0,70 & 0,29 & 0,25 & 0,38 & - & 0,48 \\
\hline
\end{tabular}

\section{Choque térmico assistido pelo módulo elástico}

A queda da rigidez do material pela ciclagem térmica foi acompanhada pela variação do módulo elástico, com o intuito de avaliar a capacidade do refratário em resistir o início e propagação de trincas que deterioram sua resistência mecânica.

Observa-se que quanto maior a resistência do material

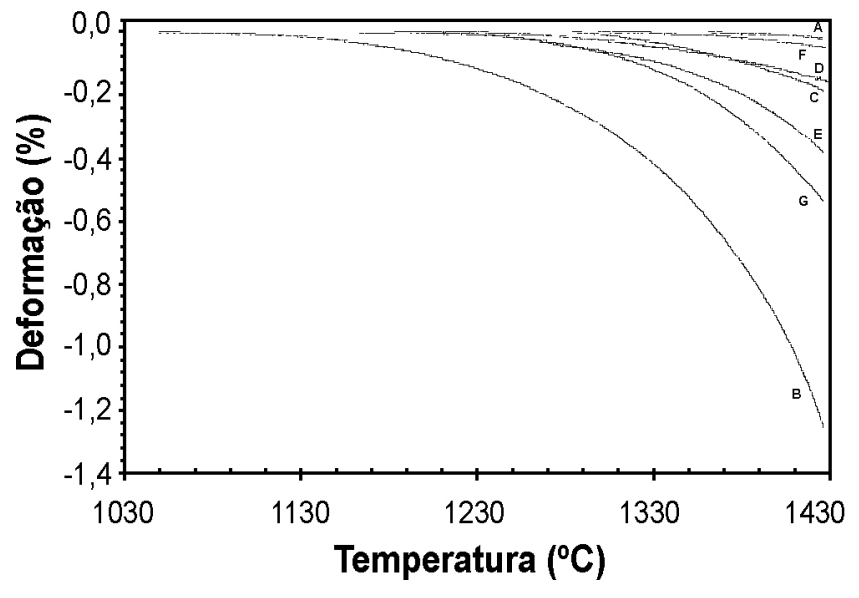

Figura 5: Refratariedade sob carga.

[Figure 5: Refractoriness under load.]

Tabela V - Temperatura de amolecimento e temperatura para deformação de $0,5 \%$.

[Table V-Softening point temperature and $0.5 \%$ deformation temperature.]

\begin{tabular}{cccccccc}
\hline & $\mathrm{A}$ & $\mathrm{B}$ & $\mathrm{C}$ & $\mathrm{D}$ & $\mathrm{E}$ & $\mathrm{F}$ & $\mathrm{G}$ \\
\hline $\mathrm{T}_{\text {amol }}$ & 1361 & 1049 & 1284 & 1196 & 1200 & 1298 & 1163 \\
$\left({ }^{\circ} \mathrm{C}\right)$ & & & & & & & \\
$\mathrm{T}_{0.5 \%}$ & $>1427$ & 1347 & $>1427$ & $>1427$ & $>1427$ & $>1427$ & 1421 \\
$\left({ }^{\circ} \mathrm{C}\right)$ & & & & & & & \\
\hline
\end{tabular}

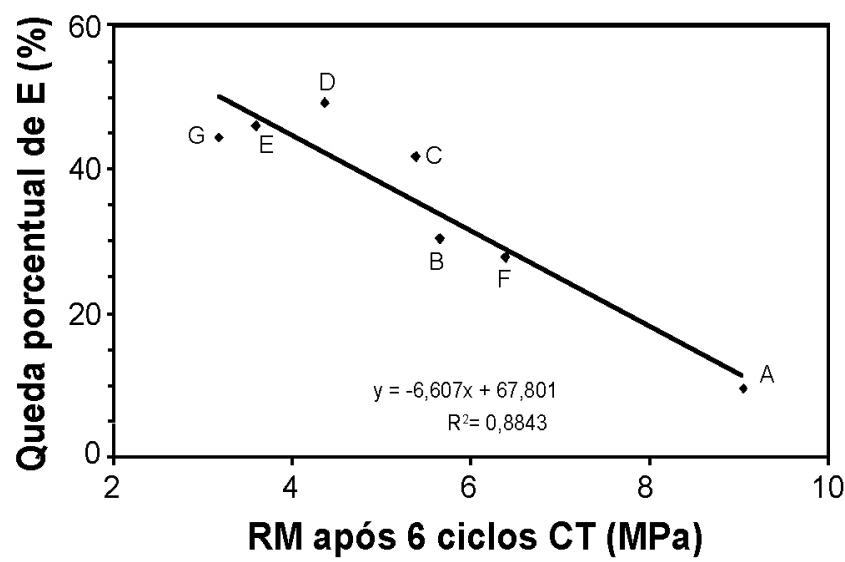

Figura 6: Correlação entre a resistência mecânica após 6 ciclos de choque térmico $\left(\Delta \mathrm{T}=1000{ }^{\circ} \mathrm{C}\right)$ e a queda porcentual do módulo elástico.

[Figure 6: Correlation between the residual mechanical strength after 6 thermal cycles $\left(\Delta T=1000{ }^{\circ} \mathrm{C}\right)$ and the elastic modulus percentage decrease.]

à fadiga térmica (menor a queda do módulo elástico), maior a resistência mecânica residual (Fig. 6). Isto pode ser observado pela composição A que obteve além de uma elevada resistência mecânica após a ciclagem térmica, a menor queda percentual da rigidez.

É importante ressaltar que o dano por choque térmico gera trincas que aumentam a permeabilidade do material. 
Desta maneira, composições que sofreram maior dano ficam mais susceptíveis a ataques químicos reduzindo a vida útil dos refratários.

\section{Resistência ao ataque químico}

Pela análise da resistência ao ataque químico dos refratários não se observou elevada degradação dos materiais, embora seja reconhecido que a criolita é a maior causadora de corrosão em tijolos refratários para cubas eletrolíticas [15].

Visualmente, todas as composições apresentaram desempenho semelhante (Fig. 7). A área atacada foi pequena, mesmo sendo o ensaio mais severo do que a aplicação, embora por um tempo muito menor que o de uso. Quantificando a área atacada, verifica-se que o material A obteve desempenho intermediário, que associado a uma excelente resistência ao choque térmico, resulta em um material superior em desempenho. Este comportamento também foi verificado nos materiais importados, C e D, que apresentaram alta resistência ao ataque químico, e desempenho intermediário na resistência ao dano por choque térmico. Desta forma, uma análise sistêmica dos resultados leva a escolha da amostra A, que, dentre as estudadas,

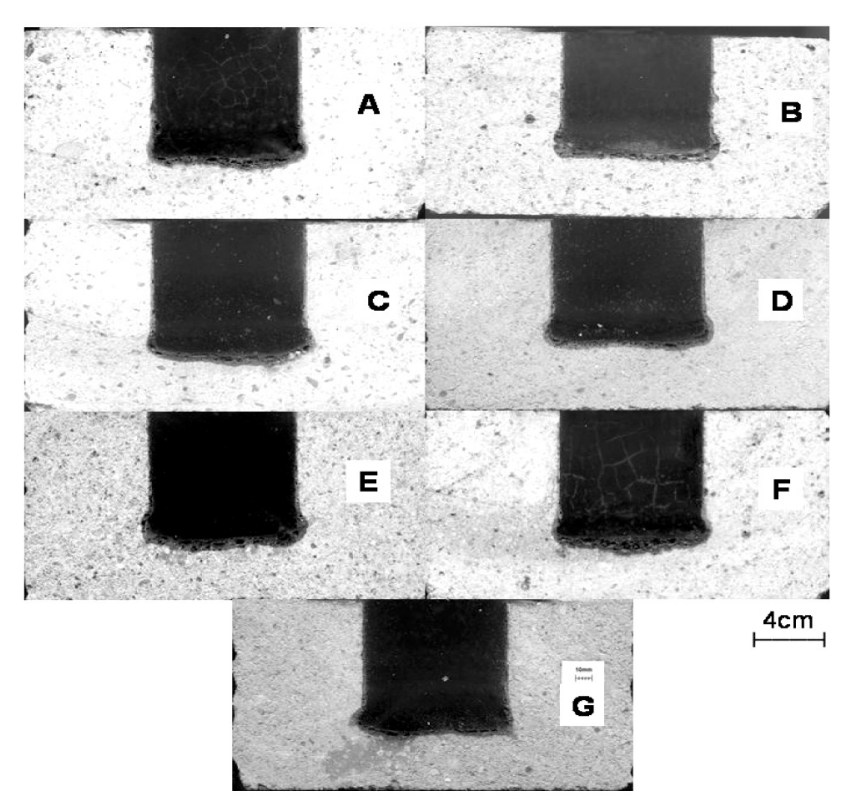

Figura 7: Ataque químico nos refratários.

[Figure 7: Refractories chemical attack.]

Tabela VI - Área atacada dos tijolos analisados [Table VI - Corroded area for the bricks analysed.]

\begin{tabular}{cccccccc}
\hline & $\mathrm{A}$ & $\mathrm{B}$ & $\mathrm{C}$ & $\mathrm{D}$ & $\mathrm{E}$ & $\mathrm{F}$ & $\mathrm{G}$ \\
\hline $\begin{array}{c}\text { Área } \\
\text { atacada } \\
\text { média } \\
\left(\mathrm{mm}^{2}\right)\end{array}$ & 400 & 408 & 348 & 318 & 424 & 427 & 284 \\
\hline
\end{tabular}

apresentou o melhor desempenho devido à associação de uma alta resistência ao dano por choque térmico, às elevada refratariedade e elevada resistência ao ataque químico.

\section{CONCLUSÕES}

A seleção do material mais adequado envolve o estudo sistêmico do projeto e práticas operacionais dos fornos, fatores comerciais e logísticos, e avaliação das propriedades que influenciam o desempenho dos refratários.

Com relação à análise técnica, parte fundamental no processo seletivo, o trabalho mostrou que os seguintes testes são imprescindíveis para a seleção da composição mais adequada: resistência mecânica a alta temperatura, fluência, refratariedade sob carga, resistência ao choque térmico, resistência ao ataque químico e análise química. Baseado nos resultados destes testes, optou-se pela escolha do material A, que apresentou microestrutura diferenciada com elevada resistência à fadiga térmica, alta refratariedade, baixa deformação a alta temperatura, e elevada resistência ao ataque por álcalis e coque. Conclui-se com isso, que a composição A atende as solicitações tanto dos refratários "Flue Wall Bricks" quanto dos "Tie Bricks", permitindo a utilização de apenas uma composição para a construção do forno, o que reduz o tempo de instalação e de manutenção dos tijolos, levando a redução no custo médio de produção do metal.

\section{AGRADECIMENTOS}

Os autores agradecem ao suporte técnico fornecido pela Alcoa Alumínio S. A. e Consórcio Alumínio do Maranhão/ Alumar para a elaboração deste trabalho. Agradecem também a contribuição dada por Lídia R. G. Gonçalves e Fernando de O. Valenzuela.

\section{REFERÊNCIAS}

[1] F. Goede, Refurbishment and modernization of existing anode baking furnaces, Light Metals (2007) 973-976.

[2] O. J. Siljan, Refractory materials for the primary aluminum industry, Ceramic News 3 (2000) 14-22.

[3] D. Maiwald, W. Leisenberg, The development of anode baking technology from past to future, Light Metals (2007) 947-952.

[4] Manual de operação dos fornos de cozimento de anodos, Alumar, documento interno (2004) 1-17.

[5] J. Carrol, A. P. Grobbelaar, Refractories for anode baking furnaces, Light Metals (1984) 543-567.

[6] M. Gendre, J. C. Rotger, Y. E. Ghaoui, N. Mathieu, A breakthrough in anode baking furnace fluewall design, Light Metals (2007) 969-972.

[7] J. Hurlen, T. Naterstad, Recent developments in carbon baking technology, JOM (1991) 20-25.

[8] G. F. Corliss, M. A. Stett, Clay alumina brick used in anode baking furnaces, JOM (1996) 29-31.

[9] D. S. Severo, V. Gusberti, E. C. V. Pinto, Advanced 3D 
modelling for anode baking furnaces, Light Metals (2005) 697-702.

[10] C. Kato, H. Truci, F. Figueiredo, A. Nascimento, V. Piffer, Alumar coke blending facility strategy, Light Metals (2007) 891-894.

[11] F. Keller, U. Mannweiler, D. Severo, Computacional modeling in anode baking, documento interno (2006) 1-12.

[12] J. Bigot, M. Gendre, J. C. Rotger, Fuel consumption: a key parameter in anode baking furnaces, Light Metals (2007) 965-968.

[13] F. Brunk, Corrosion and behaviour of fireclay bricks used in the flues of open anode baking furnaces, Light Metals (1995) 641-646.

[14] G. R. Rigby, R. Hutton, Action of alkali and alkalivanadium oxide slags on alumina-silica refractories, J. Am.
Ceram. Soc. 45, 2 (1962) 68-73.

[15] R. Pawleck, Refractory materials for aluminum electrolysis, Interceram (1976) 25-26.

[16] P. Prigent, M. L. Bouchetou, J. Poirier, Addition of andalusite in fireclay bricks for anode baking furnaces: a suitable solution to reduce gas corrosion, $10^{\text {th }}$ Biennial Worldwide Cong. Refractories (2007) 420-423.

[17] B. Ghosh, R. K. Sinha, A. K. Chattopadhyay, Alumino silicate refractories for special applications in non-ferrous mettalurgy: processing and microstructure, $9^{\text {th }}$ Biennal Worldwide Cong. Refractories (2005) 652-655.

[18] M. Jafari, M. Taddaiion, M. Hejazi, K. Forchani, Development in anode baking refractories for aluminum industry, $7^{\text {th }}$ Biennal Worldwide Cong. Refractories (2001) 690-696.

(Rec. 25/03/2008, Ac. 04/07/2008) 